\title{
دراسة واقع دليل مدرس التربية الرياضية باستعمال التحليل الرياعي (SWOT) من وجهة نظر المدرسين للمرحلة المتوسطة في مدينة بغداد
}

زينة إبراهيم مهدي(1)، صلاح وهاب شاكر (2)

\begin{abstract}
المستخلص
هدفت الدراسة اعداد استبانة التحليل الرباعي (SWOT) للاليل مدرس التربية الرياضة. والتعرف على واقع نطبيق دليل درس التربية

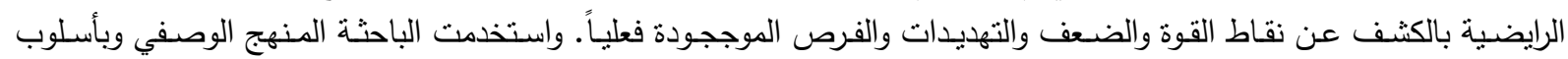
المسحي التحليلي، لملاعمته منطلبات الدراسة. وتم اختيار عينة البحث بالطريقة العددية وتمثلت بمدرسي ومدرسات التربية الرياضية

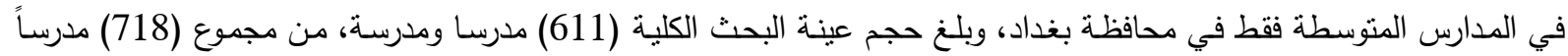
ومدرسـة بنسبة مئويـة مقدارها (85.09\%) وبلغـت عينـة التجربـة الرئيسـة للبحث (458) مدرسـاً ومدرسـة بنسـبة مئويـة مقدارها

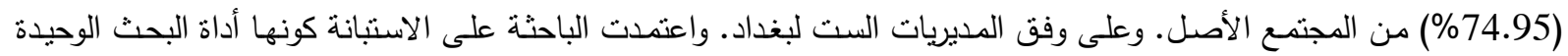

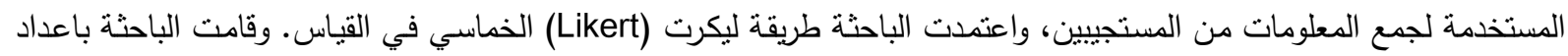
عبارات الاستبانة بالاعتماد على واقع الحال الموجود في المدارس من خلال المقابلات الثخصية والزيارات الميدانية والدليل المعتمد

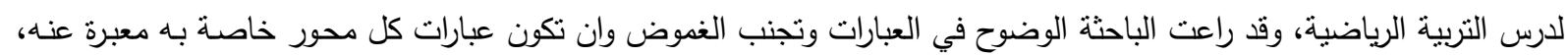

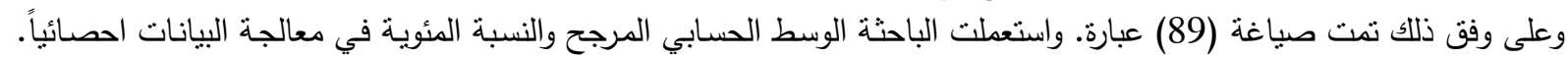

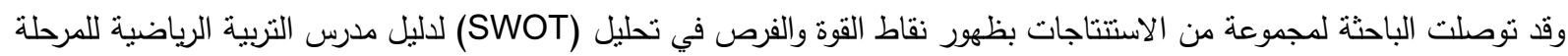

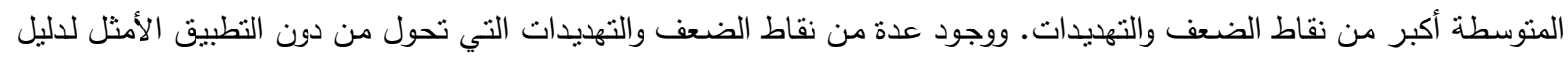

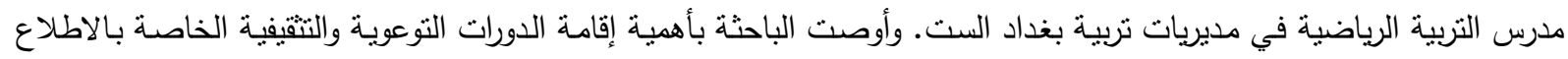

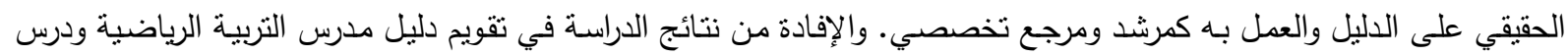

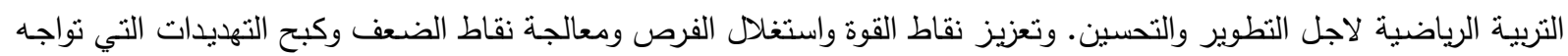

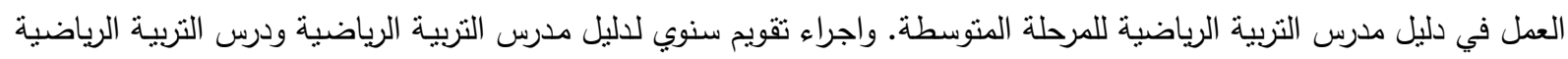

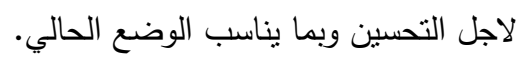
الكلمات المفتاحية: المشرفون التربويون، دليل التربية الرياضية، تحليل سوات، الددارس المتوسطة
\end{abstract}

\section{ABSTRACT \\ Studying Physical Educator Manual Reality Using SWOT from Secondary School Teachers' Point of View in Baghdad}

The research aimed at designing a SWOT questionnaire for physical educators" manual as well as identifying the reality of this manual. The researchers used the descriptive method. The subjects were (458) secondary school physical educators in Baghdad. The researchers applied a questionnaire following Likert method for measurement by designing the items of the questionnaire depending on school realities through personal interview and field visits. The researchers designed (89) items to conclude weaknesses and threats after SWOT analyses of the manual. Finally they recommended holding awareness and special educational courses to guide physical educators about the manual as well as benefiting from this research's results to modify physical educators' 'manual. In addition to that, the researchers recommended making annual evaluation for physical educators and physical education class for improvement and development.

Keywords: physical educators, manual, SWOT, secondary school.

(1) طالبة دراسات عليا (الدكتوراه)، جامعة بغداد، كلبة التربية البننية وعلوم الرياضة. (zina852000@yahoo.com) Zina Ibrahim Mahdi, Post Graduate Student (P.HD), University of Baghdad, College of Physical Education and Sport Sciences, (zina852000@yahoo.com). (+9647719452352)

(2alahalkindi62@gmail.com) أستا مساعد، دكتوراه تربية رياضية، جامعة بغداد، كلبة التربية البننية وعلوم الرياضة. Salah Wahaab Shaker, Assist prof (PH.D), Baghdad University, College of Physical Education and Sport Sciences, (salahalkindi62@gmail.com). (+9647707388166) 
تعتمد الدول الناجحة والمتقدمة على مراجعة برامجها المعدة بشكل دوري وتقويمها بصورة مستمرة والثقويم، هو العملية التي يجريها المربي، سواء كان معلما او مدرسا وكل حسب مجال عمله واختصاصه لغرض التعرف على مدى الاستفادة

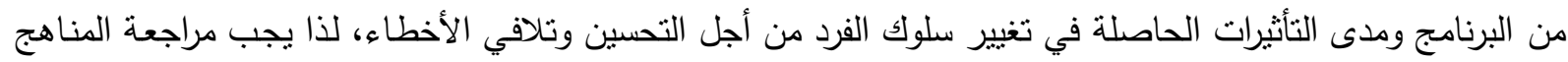
وتقويمها وتحسينها بين من زمن لأخر • وان دليل مدرس التربية الرياضية للمرحلة المتوسطة في العراق وما يحتويـه من مفاهيم واهداف يرجى تحقيقها، يحتاج الى تقويم مستمر لمعرفة ما يحققه الدليل من تللك الاهداف، إذ "يُعد الثقويم جزءا

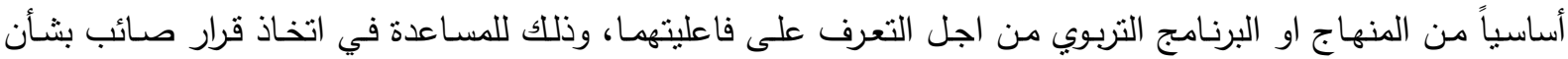
الاستمرار فيه او تعديله وتطويره" (محمد و عبدالعظيم، 2010، صفحة 291)

ان تقويم دليل درس التربية الرياضية والوقوف على ما يحتويه من نقاط القوة والضعف تساعد على الاعداد الجيد والتخطيط المناسب لـه الذي ينعكس بدوره على المدرس والطالب كونـه الأسـاس في العملية التربوية، واستغلال الفرص الموجودة في البيئة المحيطة التي تساعد على العمل والتوسعة وتلبية احتياجات الدرس والتخلص من التهديدات التي تؤثر وتقيد الحركة الرياضية والتخطيط لتفاديها والتعامل معها وتقيدها ان كانت واقعة لمحالة، لذا يُعد تحليل (SWOT) أسلوب

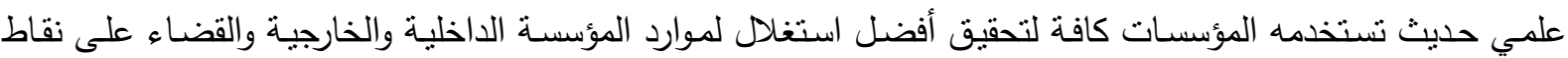
الضعف والتهديد.

ويطلق علمـاء الإدارة على هذه الخطوة التحليل الاستراتيجي او التحليل البيئي او التحليل الربـاعي ويسمى أحيانا

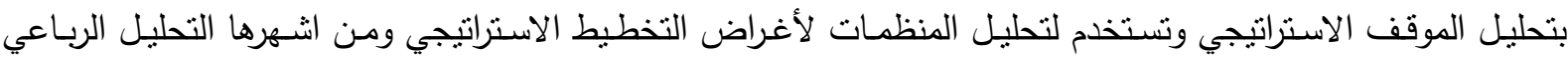
للبيئتين الداخلية والخارجية والمعروف اختصـارا (SWOT) والاحرف الأولى من جوانب القوة (Strengths)، والضعف (Weaknesses)، والفرص (Opportunities)، والتهديدات (Threats)، ويتضمن تحليل البيئة الداخليـة للمنظمـة في تحديد جوانب القوة وجوانب الضعف، بينما يتضمن تحليل البيئة الخارجية في تحديد الفرص المتاحة والتهديدات المحتملة الموجودة في المجتمع المحلي والوطني العالي ويُعد تحليل (SWOT) الأشهر في النظم التربوية. والتحليل الاستراتيجي ضروري لتحديد الأنشطة التي ستمارسها المؤسسة التعليمية او الغاء بعض الأنشطة التي تتكل

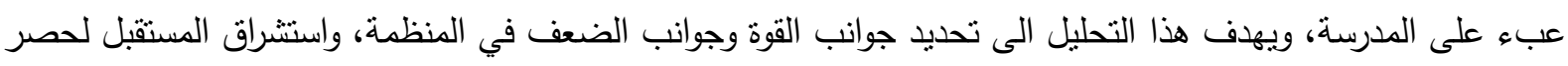

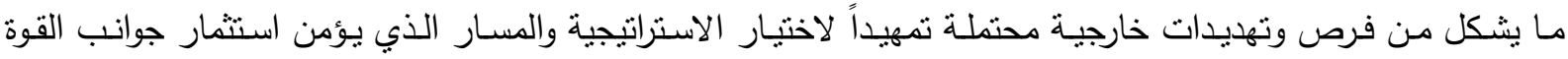
والفرص ومواجهة جوانب الضعف والتهديدات (الصميدعي و يوسف، 2011). ويعرف الصميدعي التحليل البيئي بانه: أداة للمساعدة في اتخاذ القرار ، وكذلك كأداة للتخطيط المستقبلي لكون تطبيقه مرناً في المراحل المختلفة من دورة اتخاذ

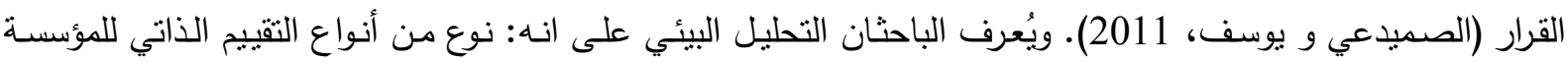
ويعتمد على البيئة الداخلية للمؤسسة (نقاط القوة، نقاط الضعف)، والبيئة الخارجية للمؤسسة (الفرص، والتهديدات)، لتحقيق افضل استخلال للموارد البشرية والمادية للمؤسسة.

إذ تبرز أهمية التحليل البيئي في انه يعطى صورة لمستقبل المنظمة وليس لحاضرها فقط الامر الذي يساعد على وضع خطط وبدائل استراتيجية تأخذ بنظر الاعتبار توقعات التغيرات البيئة المحتملة ومدى إمكانيـة تأثيرها في أنشطة فئه

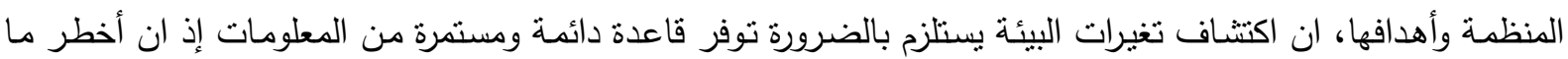

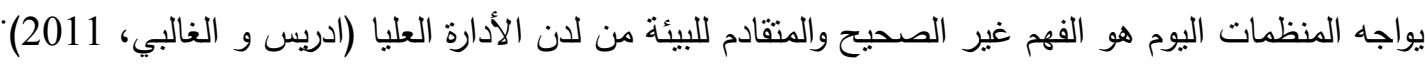
ويرى الباحثان ان تحليل (SWOT) يشكل اليوم سمة من سمات العصر وما من دولة تسعى الى تحقيق التقدم

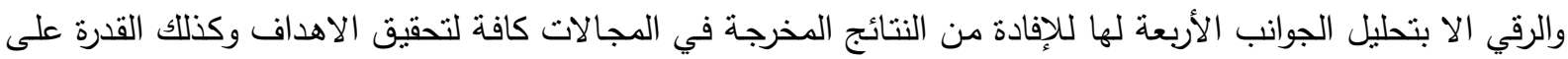
مواجهة التعقيدات والتغيرات الكثيرة التي تحدث في البيئة التربوية التعليمية. 
ومن خلال ملاحظة الباحين، لم يشهـ درس التربية الرياضية ولا الرياضة المدرسية تطوراً وتقدماً ملحوظاً منذ اعوام

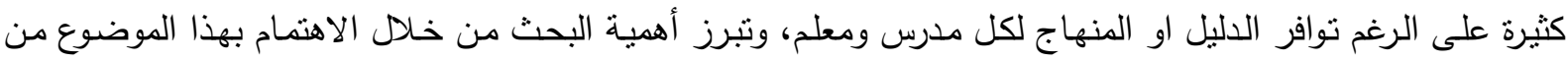

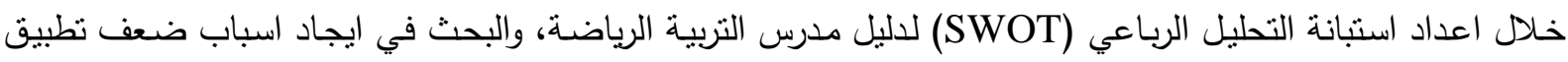

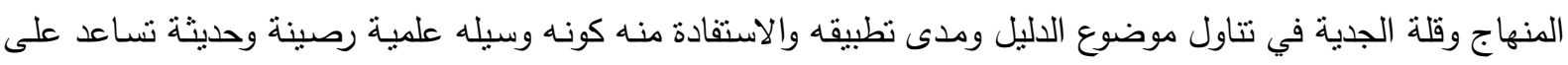
تحقيق اهداف درس التربية الرياضية، فمن الضروري اخضاع الدليل الخاص بالمرحلة المتوسطة للاراسة والتحليل والتقويم،

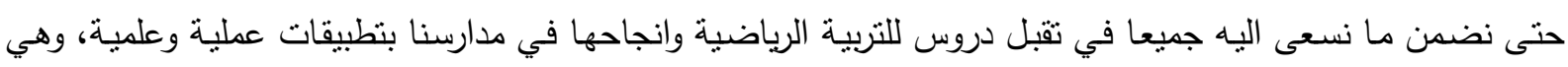

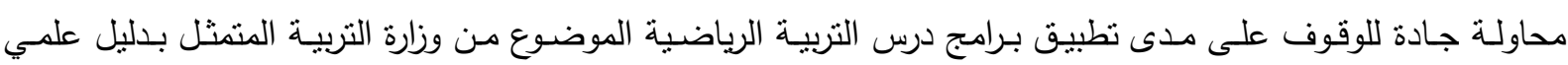

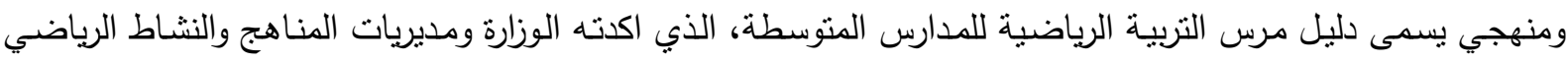
والكثفي وبأوامر رسمية للاهنمام بالدليل ودروس التربية الرياضية ومدى التطور الحاصل نتيجة لنطبيقه من لدن الإدارات والملاكات التعليمية المتمنتة بمدرسي التربية الرياضية وسعيها في توفير كل ما بلزم و بالقدر المستطاع من أدوات وأجهزة

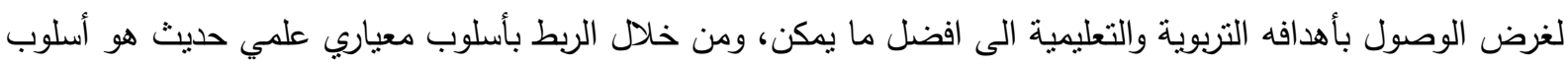

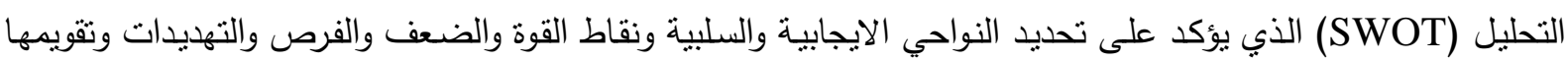
وإعطاء الحلول المناسبة ووضعها أمام طاولة المسؤولين في وزارة التربية ليساعد على تقديم معلومات عملية محركة لجودة الأداء كونها دراسة نقييم لواقع درس التربية الرياضية، وبالتالي الارتقاء بواقع الرياضة المدرسية العراقية.

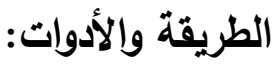

استخدم الباحثان المنهج الوصفي وبأسلوب المسحي التحليلي، لملاعمته منطلبات الدراسة، ونم اختبار عينة البحث بالطريقة العمدية وتمثلت بمدرسي ومدرسات التربية الرياضية في المدارس المتوسطة فقط في محافظة بغداد، وبلغ حجم

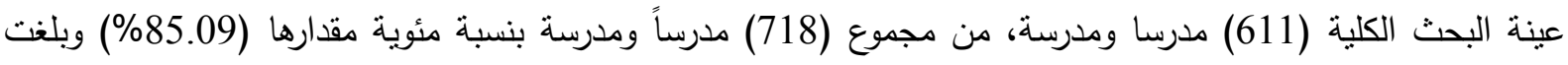

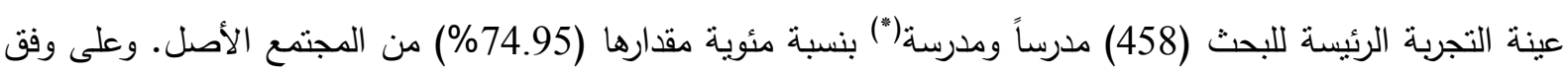
المديريات الست لبغداد وعلى وفق الاتي: مديرية الرصافة الأولى (47) مدرساً ومدرسة، ومديرية الرصافة الثانية (48)

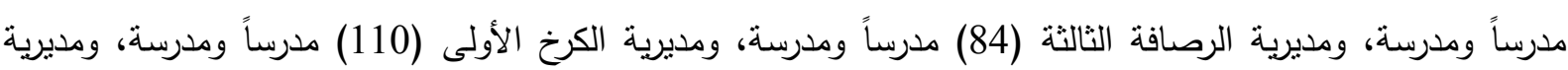

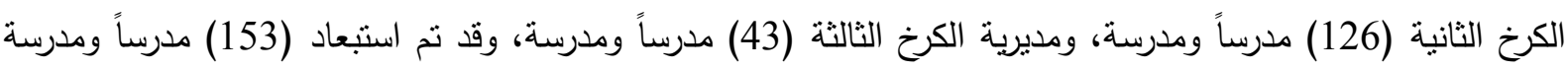

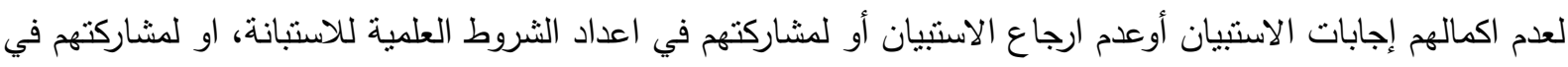
التجربة الاستطلاعية.

واعتمد الباحثان على الاستبانة كونها أداة البحث الوحيدة المستخدمة لجمع المعلومات من المستجيبين، فضلا عن

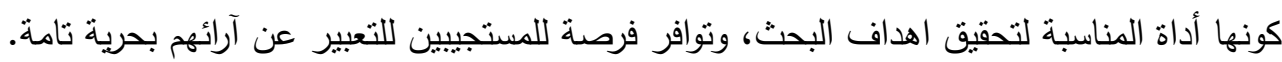

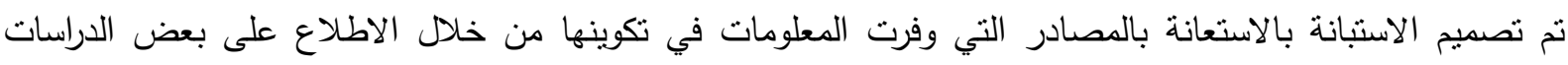

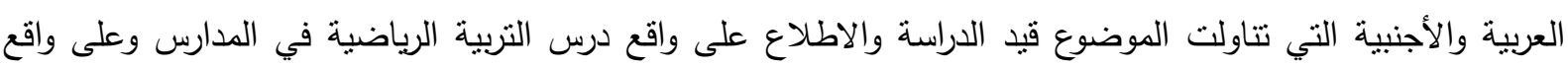
توافر الملاعب والأجهزة والمعدات المقابلات الثخصية مع بعض المختصين في مجال البحث. واعتمد الباحثان طريقة ليكرت (Likert) الخماسي في القياس كونها تتتاسب مع طبيعة البحث وطبيعة الاستبانة. إذ يُعد من اكثر المقاييس استخداماً في البحوث المسحية الذي يستعمل نمط الأسئلة المغلقة ويبين المستجيب قوة موافقته من عدمها على العبارات، وان عدد الاستجابات في مقياس ليكرت نتراوح بين (3-9) استجابات وعلى ان تكون المسافة منساوية بين الاستجابات.

(Thomas \& Nelson, 1996)

(") بلغ الوسط الحسابي لمدة خدمة عينة البحث (11.623) سنة للأكور، و (14.394) سنة للإناث، تم الحصول على عدد العينة من خلال المقابلات الثخصية مع مدراء النثاط الرياضي والكثفي للمديريات بغداد الست. 
وتميز مقياس ليكرت ولكونه: الطريقة الأكثر استخداماً في القياس، ويعطي حرية اكبر للإجابة وللتعبير عن اتجاه العبارة لوجود بدائل عدة، وان لتعدد البدائل يزيد من ثبات الاستمارة كون الإجابة تكون بين الموافقة التامة والرفض التام.

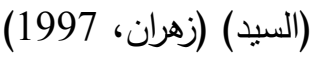

وكان احتساب الاوزان باتجاه إيجابي من (1-5) وعلى وفق البدائل أوافق بثدة (5 درجات)، أوافق (4 درجات)، أحياناً (3 درجات)، لا أوافق (2 درجتان)، لا أوافق بشدة (1 درجة). ونم اعداد عبارات الاسنبانة بالاعنماد على واقع الحال الموجود في المدارس من خلال المقابلات الثخصية والزيارات الميدانية والدليل المعتمد لدرس التربية الرياضية، وتم مراعاة الوضوح في العبارات وتجنب الغموض وان تكون عبارات كل محور خاصة به معبرة عنه، وعلى وفق ذلك تمت صياغة

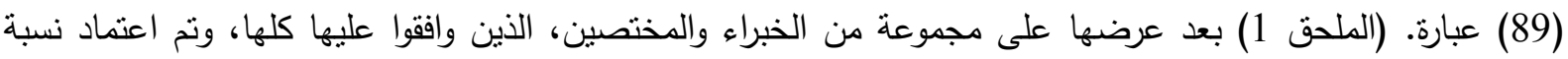

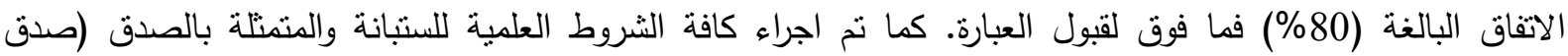
المحتوى والاتساق الداخلي) والثبات (التجزئة النصفية ومعامل الفاكورنباخ) والموضوعية والقوة التمميزية للاستبانة ومعامل الصعوية والسهولة. وقام الباحثان بإجراء تجربة استطلاعية على عينة من مدرسي التربية الرياضية والبالغ عددها (14) مدرساً ومدرسة

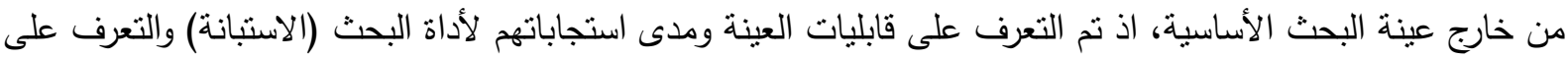

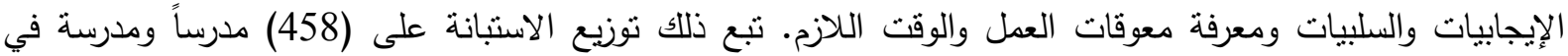

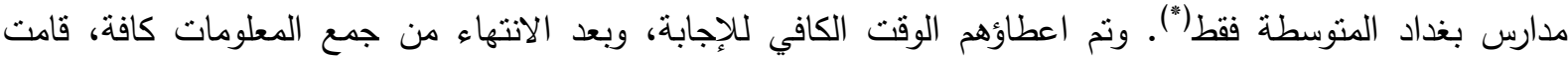
الباحثة بتفريغ الاستمارات تمهيداً للعمل الاحصائي للحصول على النتائج بالاعتماد على برنامج لونه (SPSS).

الجدول (1) يبين تكرارات البدائل ونسبها المئوية والوسط الحسابي المرجح والأهمية النسبية للعبارات وتقديرها اللفظي لعبارات استبانة (SWOT) لمديريات تربية بغداد الست

\begin{tabular}{|c|c|c|c|c|c|c|c|c|c|c|c|c|c|c|}
\hline \multicolumn{4}{|c|}{ المعالم الإحصائية } & \multicolumn{10}{|c|}{ البدائل } & \multirow{3}{*}{$ت$} \\
\hline \multirow{2}{*}{ التبارة } & \multirow{2}{*}{ اللفظير } & \multirow{2}{*}{ الأهمية } & \multirow{2}{*}{ سرَّ المرجع } & \multicolumn{2}{|c|}{ لا أوافق بشدة } & \multicolumn{2}{|c|}{ لا أوافق } & \multicolumn{2}{|c|}{ احياناً } & \multicolumn{2}{|c|}{ اوافق } & \multicolumn{2}{|c|}{ أوافق بشدة } & \\
\hline & & & & $\%$ & s & $\%$ & s & $\%$ & ك & $\%$ & ك & $\%$ & s & \\
\hline قوة & كبير جداً & 91.09 & 4.55 & 0.22 & 1 & 1.53 & 7 & 3.93 & 18 & 31.22 & 143 & 63.10 & 289 & 1 \\
\hline قوة & كبير & 71.70 & 3.59 & 1.75 & 8 & 7.86 & 36 & 36.46 & 167 & 37.99 & 174 & 15.94 & 73 & 2 \\
\hline قوة ق ق ق ق & كبير & 77.21 & 3.86 & 0.66 & 3 & 3.71 & 17 & 27.95 & 128 & 44.32 & 203 & 23.36 & 107 & 3 \\
\hline قوة & كبير & 79.39 & 3.97 & 4.59 & 21 & 7.21 & 33 & 19.21 & 88 & 24.67 & 113 & 44.32 & 203 & 4 \\
\hline قوة ق ق ق ق ق & كبير & 75.85 & 3.79 & 11.14 & 51 & 9.17 & 42 & 13.10 & 60 & 22.49 & 103 & 44.10 & 202 & 5 \\
\hline قوة ق ق & كبير & 80.31 & 4.02 & 2.40 & 11 & 2.84 & 13 & 21.83 & 100 & 36.68 & 168 & 36.24 & 166 & 6 \\
\hline قوة & كبير & 70.22 & 3.51 & 2.62 & 12 & 6.11 & 28 & 44.76 & 205 & 30.57 & 140 & 15.94 & 73 & 7 \\
\hline قوة & كبير & 73.89 & 3.69 & 2.18 & 10 & 7.64 & 35 & 30.13 & 138 & 38.65 & 177 & 21.40 & 98 & 8 \\
\hline قوة & كبير & 73.49 & 3.67 & 3.49 & 16 & 4.80 & 22 & 29.48 & 135 & 45.20 & 207 & 17.03 & 78 & 9 \\
\hline قوة & كبير & 71.22 & 3.56 & 1.53 & 7 & 8.08 & 37 & 37.12 & 170 & 39.30 & 180 & 13.97 & 64 & 10 \\
\hline قوة & كبير & 75.02 & 3.75 & 1.97 & 9 & 6.33 & 29 & 27.73 & 127 & 42.58 & 195 & 21.40 & 98 & 11 \\
\hline قوة & كبير & 74.85 & 3.74 & 3.28 & 15 & 6.11 & 28 & 25.55 & 117 & 43.23 & 198 & 21.83 & 100 & 12 \\
\hline قوة & كبير & 77.64 & 3.88 & 3.49 & 16 & 3.71 & 17 & 24.89 & 114 & 36.90 & 169 & 31.00 & 142 & 13 \\
\hline قوة & كبير & 75.02 & 3.75 & 2.62 & 12 & 4.80 & 22 & 30.13 & 138 & 39.74 & 182 & 22.71 & 104 & 14 \\
\hline قوة & كبير & 72.62 & 3.63 & 2.84 & 13 & 8.08 & 37 & 30.79 & 141 & 39.74 & 182 & 18.56 & 85 & 15 \\
\hline قوة & كبير & 74.10 & 3.71 & 1.09 & 5 & 8.30 & 38 & 30.13 & 138 & 39.96 & 183 & 20.52 & 94 & 16 \\
\hline
\end{tabular}


مهلة التربية الرياضية - المجلد (32) - العدد (1) - سنة 2020.

\begin{tabular}{|c|c|c|c|c|c|c|c|c|c|c|c|c|c|c|}
\hline قوة & كبير & 77.99 & 3.90 & 0.66 & 3 & 3.49 & 16 & 22.93 & 105 & 51.09 & 234 & 21.83 & 100 & 17 \\
\hline قوة & كبير & 73.80 & 3.69 & 1.97 & 9 & 6.99 & 32 & 30.57 & 140 & 41.05 & 188 & 19.43 & 89 & 18 \\
\hline قوة & متوسط & 65.24 & 3.26 & 9.17 & 42 & 18.34 & 84 & 30.79 & 141 & 20.52 & 94 & 21.18 & 97 & 19 \\
\hline قوة & كبير & 72.05 & 3.60 & 1.97 & 9 & 11.35 & 52 & 30.57 & 140 & 36.68 & 168 & 19.43 & 89 & 20 \\
\hline قوة & كبير & 76.51 & 3.83 & 1.97 & 9 & 5.02 & 23 & 25.11 & 115 & 44.32 & 203 & 23.58 & 108 & 21 \\
\hline قوة & كبير & 73.14 & 3.66 & 2.84 & 13 & 8.08 & 37 & 27.73 & 127 & 43.23 & 198 & 18.12 & 83 & 22 \\
\hline قوة & كبير & 72.93 & 3.65 & 2.62 & 12 & 7.86 & 36 & 31.22 & 143 & 38.86 & 178 & 19.43 & 89 & 23 \\
\hline فرص & كبير & 73.28 & 3.66 & 2.18 & 10 & 7.64 & 35 & 30.79 & 141 & 40.39 & 185 & 19.00 & 87 & 24 \\
\hline فرص & كبير & 73.71 & 3.69 & 3.71 & 17 & 6.33 & 29 & 27.95 & 128 & 41.70 & 191 & 20.31 & 93 & 25 \\
\hline فرص & كبير & 69.21 & 3.46 & 8.30 & 38 & 11.14 & 51 & 26.20 & 120 & 34.93 & 160 & 19.43 & 89 & 26 \\
\hline فرص & كبير & 74.89 & 3.74 & 1.97 & 9 & 6.77 & 31 & 25.76 & 118 & 45.85 & 210 & 19.65 & 90 & 27 \\
\hline فرص & كبيز & 76.03 & $\mathbf{3 . 8 0}$ & 1.09 & 5 & 5.02 & 23 & 26.64 & 122 & 47.16 & 216 & 20.09 & 92 & 28 \\
\hline فرص & كبير & 72.01 & 3.60 & 3.28 & 15 & 8.52 & 39 & 31.00 & 142 & $\mathbf{3 9 . 3 0}$ & 180 & 17.90 & 82 & 29 \\
\hline فرص & كبير & 72.36 & 3.62 & 2.18 & 10 & 7.21 & 33 & 35.37 & 162 & $\mathbf{3 7 . 1 2}$ & 170 & 18.12 & 83 & 30 \\
\hline فرص & كبير & 68.47 & 3.42 & 5.02 & 23 & 10.04 & 46 & 36.24 & 166 & 34.93 & 160 & 13.76 & 63 & 31 \\
\hline فرص & كبير & 76.42 & 3.82 & 2.18 & 10 & 5.46 & 25 & 25.76 & 118 & 41.27 & 189 & 25.33 & 116 & 32 \\
\hline فرص & كبير & 76.29 & 3.81 & 1.97 & 9 & 3.93 & 18 & 27.73 & 127 & 43.45 & 199 & 22.93 & 105 & 33 \\
\hline فرص & كبير & 74.06 & 3.70 & 1.75 & 8 & 7.42 & 34 & 29.04 & 133 & 42.36 & 194 & 19.43 & 89 & 34 \\
\hline فرص & كبير & 69.87 & 3.49 & 6.55 & 30 & 10.70 & 49 & 28.17 & 129 & 36.03 & 165 & 18.56 & 85 & 35 \\
\hline فرص & كبير & 72.36 & 3.62 & 3.06 & 14 & 7.64 & 35 & 31.22 & 143 & 40.61 & 186 & 17.47 & 80 & 36 \\
\hline فرص & كبير & 70.26 & 3.51 & 3.49 & 16 & 10.70 & 49 & 31.66 & 145 & $\mathbf{3 9 . 3 0}$ & 180 & 14.85 & 68 & 37 \\
\hline فرص & كبير & 74.15 & 3.71 & 1.75 & 8 & 6.77 & 31 & 29.91 & 137 & 42.14 & 193 & 19.43 & 89 & 38 \\
\hline فرص & كبير & 72.40 & 3.62 & 1.75 & 8 & 10.26 & 47 & 30.79 & 141 & 38.65 & 177 & 18.56 & 85 & 39 \\
\hline فرص & متوسط & 67.64 & $\mathbf{3 . 3 8}$ & 10.48 & 48 & 12.88 & 59 & 26.42 & 121 & 28.38 & 130 & 21.83 & 100 & 40 \\
\hline فرص & كبير & 72.49 & 3.62 & 5.02 & 23 & 10.92 & 50 & 26.64 & 122 & 31.44 & 144 & 25.98 & 119 & 41 \\
\hline فرص & متوسط & 67.90 & 3.40 & 11.57 & 53 & 11.79 & 54 & 27.07 & 124 & 24.67 & 113 & 24.89 & 114 & 42 \\
\hline فرص & كبير & 74.67 & 3.73 & 3.49 & 16 & 9.17 & 42 & 25.76 & 118 & 33.62 & 154 & 27.95 & 128 & 43 \\
\hline فرص & كبير & 77.21 & 3.86 & 1.53 & 7 & 3.71 & 17 & 26.86 & 123 & 43.01 & 197 & 24.89 & 114 & 44 \\
\hline فرص & كبير & 75.24 & 3.76 & 3.06 & 14 & 5.90 & 27 & 26.86 & 123 & 40.17 & 184 & 24.02 & 110 & 45 \\
\hline تهايد & كبير & 69.65 & 3.48 & 3.93 & 18 & 12.01 & 55 & 34.06 & 156 & 31.88 & 146 & 18.12 & 83 & 46 \\
\hline تهايد & متوسط & 63.62 & 3.18 & 5.46 & 25 & 19.43 & 89 & 38.65 & 177 & 24.45 & 112 & 12.01 & 55 & 47 \\
\hline تهايد & متوسط & 67.16 & 3.36 & 3.71 & 17 & 19.43 & 89 & 33.41 & 153 & 24.24 & 111 & 19.21 & 88 & 48 \\
\hline تهايد & متوسط & 62.10 & 3.10 & 3.49 & 16 & 27.51 & 126 & 35.37 & 162 & 22.27 & 102 & 11.35 & 52 & 49 \\
\hline تهايد & كبير & 71.35 & 3.57 & 3.28 & 15 & 9.61 & 44 & 34.93 & 160 & 31.44 & 144 & 20.74 & 95 & 50 \\
\hline تهايد & متوسط & $\mathbf{5 7 . 4 7}$ & 2.87 & 16.81 & 77 & 24.45 & 112 & 28.38 & 130 & 15.28 & 70 & 15.07 & 69 & 51 \\
\hline تهايد & متوسط & 63.97 & 3.20 & 11.57 & 53 & 20.74 & 95 & 24.89 & 114 & 21.83 & 100 & 20.96 & 96 & 52 \\
\hline تهايد & كبير & 76.72 & 3.84 & 5.68 & 26 & 6.33 & 29 & 22.71 & 104 & 29.26 & 134 & 36.03 & 165 & 53 \\
\hline تهايد & كبير & 73.67 & 3.68 & 1.31 & 6 & 6.99 & 32 & 32.97 & 151 & 39.52 & 181 & 19.21 & 88 & 54 \\
\hline تهايد & كبير & 73.06 & 3.65 & 1.53 & 7 & 5.24 & 24 & 36.68 & 168 & 39.52 & 181 & 17.03 & 78 & 55 \\
\hline تهايد & كبير & 72.79 & 3.64 & 4.80 & 22 & 9.83 & 45 & 27.07 & 124 & 33.19 & 152 & 25.11 & 115 & 56 \\
\hline تهايد & كبير & 72.49 & 3.62 & 3.28 & 15 & 8.30 & 38 & 30.79 & 141 & 37.99 & 174 & 19.65 & 90 & 57 \\
\hline تهايد & متوسط & 60.35 & 3.02 & 7.64 & 35 & 28.38 & 130 & 29.04 & 133 & 24.45 & 112 & 10.48 & 48 & 58 \\
\hline تهايد & كبير & 73.54 & 3.68 & 3.49 & 16 & 5.90 & 27 & 29.69 & 136 & 41.27 & 189 & 19.65 & 90 & 59 \\
\hline تهايد & كبير & 71.09 & 3.55 & 4.37 & 20 & 10.70 & 49 & 30.79 & 141 & 33.41 & 153 & 20.74 & 95 & 60 \\
\hline تهايد & كبير & 73.49 & 3.67 & 5.02 & 23 & 6.99 & 32 & 27.95 & 128 & 35.59 & 163 & 24.45 & 112 & 61 \\
\hline تهايد & كبير & 74.80 & 3.74 & 3.93 & 18 & 5.24 & 24 & 28.60 & 131 & 37.34 & 171 & 24.89 & 114 & 62 \\
\hline تهايد & كبير & 74.76 & 3.74 & 8.08 & 37 & 9.39 & 43 & 19.65 & 90 & 26.42 & 121 & 36.46 & 167 & 63 \\
\hline تهايد & كبير & 75.20 & 3.76 & 2.84 & 13 & 6.55 & 30 & 28.60 & 131 & 35.81 & 164 & 26.20 & 120 & 64 \\
\hline
\end{tabular}




\begin{tabular}{|c|c|c|c|c|c|c|c|c|c|c|c|c|c|c|}
\hline تهديد & كبير & 68.65 & 3.43 & 10.92 & 50 & 13.10 & 60 & 24.02 & 110 & 25.76 & 118 & 26.20 & 120 & 65 \\
\hline تهديد & كبير & 73.19 & 3.66 & 3.71 & 17 & 8.52 & 39 & 28.82 & 132 & 36.03 & 165 & 22.93 & 105 & 66 \\
\hline تهايد & كبير & 72.66 & 3.63 & 2.40 & 11 & 7.64 & 35 & 35.59 & 163 & 32.97 & 151 & 21.40 & 98 & 67 \\
\hline تهايد & كبير & 72.36 & 3.62 & 3.49 & 16 & 8.08 & 37 & 30.79 & 141 & 38.43 & 176 & 19.21 & 88 & 68 \\
\hline تهايد & كبير & 76.20 & 3.81 & 0.44 & 2 & 5.90 & 27 & 29.48 & 135 & 40.61 & 186 & 23.58 & 108 & 69 \\
\hline ضعف & كبير & 73.01 & 3.65 & 3.06 & 14 & 7.64 & 35 & 33.84 & 155 & 32.10 & 147 & 23.36 & 107 & 70 \\
\hline ضعف & كبير & 79.26 & 3.96 & 2.40 & 11 & 5.24 & 24 & 22.49 & 103 & 33.41 & 153 & 36.46 & 167 & 71 \\
\hline ضعف & كبير & 78.95 & 3.95 & 4.15 & 19 & 4.15 & 19 & 20.74 & 95 & 34.72 & 159 & 36.24 & 166 & 72 \\
\hline ضعف & كبير & 79.87 & 3.99 & 3.49 & 16 & 5.02 & 23 & 19.21 & 88 & 33.19 & 152 & 39.08 & 179 & 73 \\
\hline ضعف & كبير & 74.19 & 3.71 & 3.28 & 15 & 8.52 & 39 & 26.86 & 123 & 36.68 & 168 & 24.67 & 113 & 74 \\
\hline ضعف & كبير & 74.45 & 3.72 & 2.62 & 12 & 8.08 & 37 & 29.69 & 136 & 33.62 & 154 & 25.98 & 119 & 75 \\
\hline ضعف & متوسط & 62.97 & 3.15 & 13.32 & 61 & 16.81 & 77 & 29.91 & 137 & 21.62 & 99 & 18.34 & 84 & 76 \\
\hline ضعف & كبير & 71.53 & 3.58 & 11.35 & 52 & 13.97 & 64 & 16.38 & 75 & 22.27 & 102 & 36.03 & 165 & 77 \\
\hline ضعف & كبير & 70.00 & 3.50 & 3.93 & 18 & 9.83 & 45 & 38.65 & 177 & 27.51 & 126 & 20.09 & 92 & 78 \\
\hline ضعف & كبير & 76.16 & 3.81 & 5.24 & 24 & 10.26 & 47 & 19.43 & 89 & 28.60 & 131 & 36.46 & 167 & 79 \\
\hline ضعف & كبير & 72.97 & 3.65 & 4.37 & 20 & 9.39 & 43 & 28.38 & 130 & 32.75 & 150 & 25.11 & 115 & 80 \\
\hline ضعف & متوسط & 63.49 & 3.17 & 13.54 & 62 & 19.00 & 87 & 26.64 & 122 & 18.12 & 83 & 22.71 & 104 & 81 \\
\hline ضعف & متوسط & 61.14 & 3.06 & 14.85 & 68 & 19.65 & 90 & 30.13 & 138 & 15.72 & 72 & 19.65 & 90 & 82 \\
\hline ضعف & كبير & 70.87 & 3.54 & 3.49 & 16 & 11.57 & 53 & 35.15 & 161 & 26.64 & 122 & 23.14 & 106 & 83 \\
\hline ضعف & كبير & 72.14 & 3.61 & 6.11 & 28 & 9.61 & 44 & 28.17 & 129 & 29.69 & 136 & 26.42 & 121 & 84 \\
\hline ضعف & متوسط & 61.40 & 3.07 & 20.31 & 93 & 16.81 & 77 & 20.96 & 96 & 19.43 & 89 & 22.49 & 103 & 85 \\
\hline ضعف & متوسط & 64.89 & 3.24 & 8.52 & 39 & 18.56 & 85 & 31.66 & 145 & 22.49 & 103 & 18.78 & 86 & 86 \\
\hline ضعف & كبير & 68.30 & 3.41 & 3.49 & 16 & 13.97 & 64 & 38.21 & 175 & 26.20 & 120 & 18.12 & 83 & 87 \\
\hline ضعف & متوسط & 66.59 & 3.33 & 5.02 & 23 & 18.34 & 84 & 33.19 & 152 & 25.55 & 117 & 17.90 & 82 & 88 \\
\hline ضعف & متوسط & 66.86 & 3.34 & 5.24 & 24 & 16.16 & 74 & 36.90 & 169 & 22.49 & 103 & 19.21 & 88 & 89 \\
\hline
\end{tabular}

من خلال الجداول السابق الذكر يتضح لنا ان عبارات الاستبيان الخاص بتحليل (SWOT) لمحاور القوة والفرص

والتهديدات والضعف قد تباينت في قيم أهميتها النسبية واوساطها الحسابية المرجحة فضلا عن التقدير اللفظي لكل عبارة ففي محور القوة حصلت العبارة الأولى (توافر العدد الكافي من مدرسي التربية الرياضية بما يتتاسب مع اعداد الطلبة) على اهمية نسبية ووسط حسابي مرجح وبتقدير لفظي (كبير جدا) في جميع مديريات تربية بغداد الست، مما يدل على حرص وزارة التربية العراقية على توفير مدرسي التربية الرياضية في المدارس العراقية وعدم اهمالها لهذا الدرس، ووجود فرص التعينات مما يسهم بشكل إيجابي وفعال في تطوير الرياضة المدرسية العراقية، اذ ان توافر مدرس التربية الرياضية في المدارس بشكل كاف ومناسب يزيد من أهمية ممارسة الرياضة المدرسية والمشاركة في البطولات فضلا عن الجانب التزفيهي والصحي المهمين الناتجين عن ممارسة النشاط البدني فضلا عن زيادة التحصيل الدراسي. ومن جانب اخر نجد ان هناك الكثير واغلب العبارات الاخرى في محور القوة كانت ذات أهمبة نسبية اكبر من (70\%) وبتقدير لفظي (كبير)، عدا بعض العبارات. مما يدل على جدية إدارة المدارس ومدرس التربية الرياضية في تطبيق الدليل بشكل نموذجي، وانه مناسب الى حد ما مع قابليات الطلبة وانه يطور من القرات البدنية للطلبة ويمكهم من

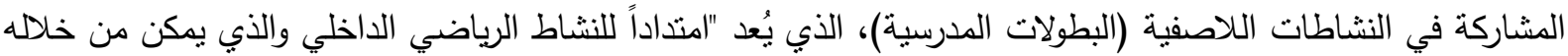
تقويم عمل المدرس خلال السنة والذي يمكن المدرس من اعداد فرق رياضية تشارك في السباقات الخارجة. (الربيعي، 2011). وانه يغطي مفردات درس التربية الرياضية بشكل جيد، وانه واضح بدرجة كافية لمدرس التربية الرياضية ومناسب

اما في محور الفرص العبارة نلاحظ ان مديريات تربية بغداد جميعها حققت أهمية نسبية في عبارات محور الفرص بقيم تراوحت بين (70-84\%) وبتقدير لفظي (كبير)، مما يدل على إمكانية استغلال هذه الفرص وتحويلها الى نقاط قوة 
يمكن الإفادة منها في تطوير الدليل وعمل مدرس التربية الرياضية بشكل عام، اذ يحوي الدليل المعد على يد خبراء

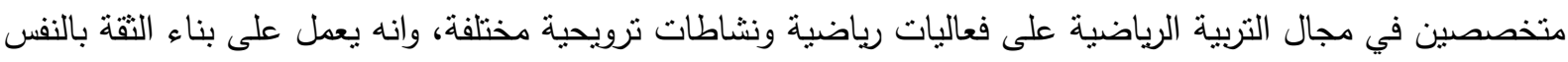
لكل من المدرس والطالب فضلا عن وجود الأبنية والساحات الكافية التي يمكن استغلالها بشكل امثل من اجل تعزيز درس وليه لئه التربية الرياضية وإمكانية ادامة وصيانة ما هو موجود بشكل جيد، فضلا عن مناسبة الدليل مع الحصص الأسبوعية وزمنها

الافتراضيين في الجدول الدراسي الأسبوعي اما في محور التهديدات والذي يمثل العوامل الخارجية المؤثرة في تطبيق دليل درس التربية الرياضية للمرحلة المتوسطة الى جانب محور الفرص، فنلحظ أيضا وجود العوامل الكثير المهددة لإنجاح عملية نطبيق الدليل التي ظهرت بأهمية نسبية عالية تراوحت بين (70-81\%) وبتقدير لفظي (كبير)، مما يدل على وجود الكثير من التهديدات التي تعيق

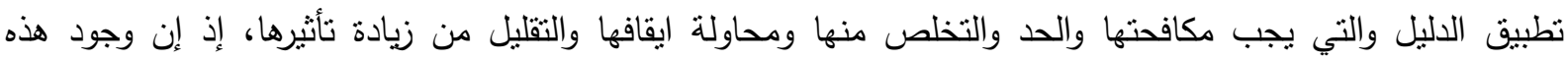

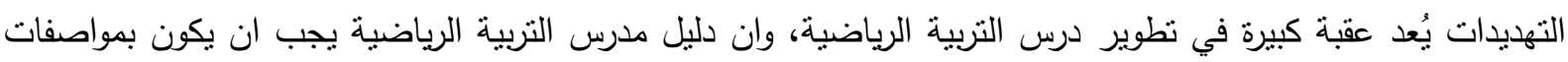

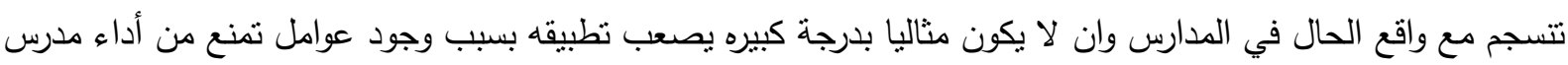
التربية الرياضية بالشكل الأمنل.

ان هذه المجموعة من التهديدات هي على قدر كبير من الأهمية وهي موازنة لأهمية نقاط القوة والفرص فمثلما يجب الأب ان تعزز من الفرص ونقاط القوة يجب ان نعالج التهديدات ونقاط الضعف وبالتالي الحصول على افضل التهن النتائج. اما في محور الضعف والذي يمتل العوامل الداخلية المؤثرة في تطبيق دليل درس التربية الرياضية، الى جانب محور القوة وهو نقيض نقاط القوة الموجودة في الدليل التي تدل على وجود ضعف في أماكن محددة يجب معالجتها والارتقاء بها من اجل تحسينها، ونلحظ من خلال الجداول التي سبق ذكرها وجود الكثير من نقاط الضعف في نطبيق دليل مدرد فئ التربية

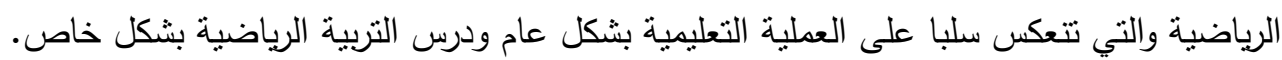

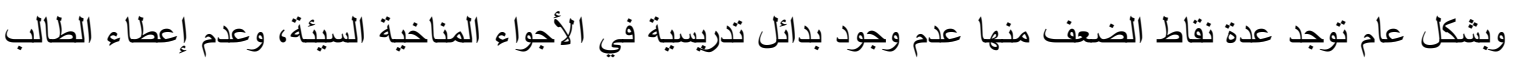

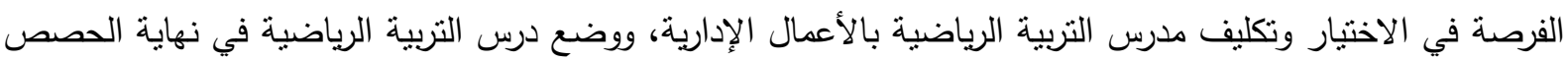

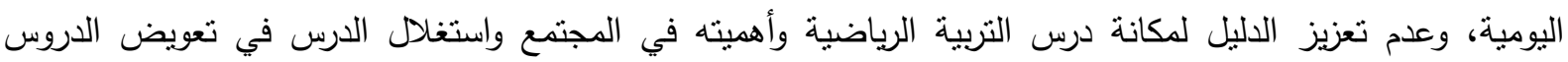

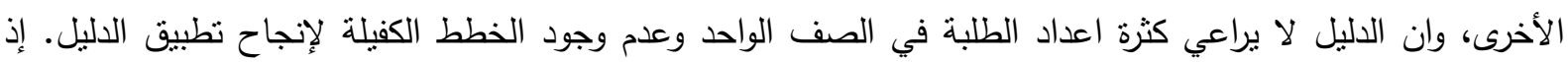
يتفق على أن الوسائل والتجهيزات والمعدات هي عناصر أساسية وضرورية لنطوير الرياضة. (Hemmatinezhad M \& Kahnazadeh S, 2009) (Farzanege \& Moosavi , 2010) وبشكل عام فان نقاط الضعف الموجودة هي كثيرة ويجب مواجنتها للحد من خطورتها ومحاولة التغلب عليها وكلها امور يمكن معالجتها من خلال خطة استراتيجية يتم وضعها من وزارة التربية لمعالجة هذه المشاكل. ومن خلال تحليل مديريات نربية بغداد واحصاءها مجتمعتا نجد ان تكرارات واهمية نسبية وتقدير لفظي (الكبير والكبير جدا) كان في محوري القوة والفرص مما ينبعي إمكانية النهوض بواقع الدليل ودروس التربية الرياضية بشكل عام

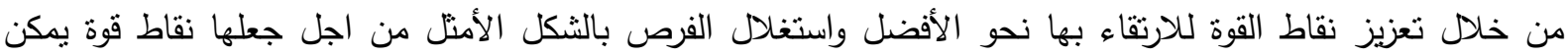
الإفادة منها، هذا الامر يمكن نطبيقه من خلال التخطيط الاستراتيجي بعيد المدى.

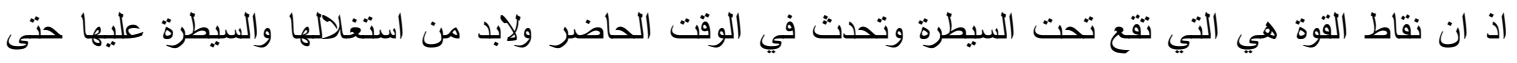
يمكن الاستغناء عن نقاط الضعف وان الفرص هي عوامل إيجابية او مساعدة منوافرة في البيئة يمكن استغلالها وهي في الغالب تكون خارج السيطرة وهي عوامل إيجابية خارجية. (الكرخي، 2016)

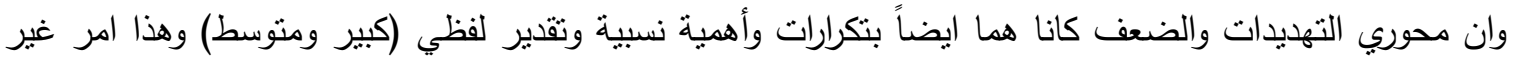
مطئن وغير جيد ويجب حل هذه الشيكلة من خلال إزالة العوامل المهددة ونقاط الضعف من اجل الارتقاء بعمل الدليل مدرس التربية الرياضية، إذ إن السيطرة على هذين المحورين يعني إمكانية إزالة العقبات التي نواجه تطبيق الدليل كافة. اذ 
ان التهديدات هي ظروف خارجية تؤثز سلبا، او قد تؤثز بشكل سلبي وهي عامل مهدد وقد يسبب ضرراً، اما في نقاط الضعف فهي الغياب الفعلي لنقاط القوة وهي عوامل نقص داخلية موجودة فعلا تعيق القدرة على الاستغلال الأمتل وهي

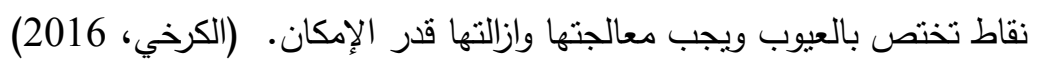

| (الاستتناجات:

• ضعف في الوعي العام لدى مدرسي التربية الرياضية نحو تطبيق الدليل كونه مرشداً حيوياً ومهماً لألية عمل مدرس التربية الرياضية.

ظهرت نقاط القوة والفرص في تحليل (SWOT) لدليل مدرس التربية الرياضية للمرحلة المتوسطة أكبر من نقاط الضعف والتهديدات.

وجود عدة من نقاط الضعف والتهديدات التي تحول من دون التطبيق الأمنل لدليل مدرس التربية الرياضية في مديريات تربية بغداد الست. الدليل جيد جداً من ناحية المواضيع والثمول لكل المعلومات التي يحتاجها المدرس خلال الدرس. أهمية إقامة الدورات التوعوية والتتقيفية الخاصة بالاطلاع الحقيقي على الدليل والعمل به كمرشد ومرجع تخصصي. الإفادة من نتائج الدراسة في تقويم دليل مدرس التربية الرياضية ودرس التربية الرياضية لاجل التطوير والتحسين. تعزيز نقاط القوة واستغلال الفرص ومعالجة نقاط الضعف وكبح التهديدات التي تواجه العمل في دليل مدرس التربية الرياضية للمرحلة المتوسطة. اجراء تقويم سنوي لدليل مدرس التربية الرياضية ودرس التربية الرياضية لاجل التحسين وبما يناسب الوضع الحالي. 


$$
\begin{aligned}
& \text { المصادر } \\
& \text { حامد عبدالسلام زهران. (1997). علم النفس الاجتماعي. القاهرة: دار عالم الكتب. } \\
& \text { مجيد الكرخي. (2016). التخطيط الاستراتيجي باستخدام الدصفوفة الرباعية SWOT. عمان: دار المنهاهج للنشر } \\
& \text { والتوزبع. } \\
& \text { محمد الطراونة ـ (2011). أثز استخدام دورة التعلم في تتمية التقكير الناقد لدى طالبات الصف العانشر الأساسي في } \\
& \text { الأردن. مجلة جامعة الابحاث ، } 292 . \\
& \text { محمد توفيق وآخرون السيد. (بلا تاريخ). لحوث في علم النفس. القاهرة: مكتبة الانجلو المصرية. } \\
& \text { محمود جاسم الصميدعي، و ردينة عثمان يوسف. (2011). التسويق الاستراتيجي (الإصدار ط2). عمان: دار الميسرة } \\
& \text { اللنشر والتنوزيع. } \\
& \text { محمود داود الربيعي. (2011). مناهج التربية البننية والرياضية. النجف: دار الضياء للطباعة والتصميم. } \\
& \text { ناجي اسعد يوسف. (1999). التنريب البلومتري. القاهرة: مركز التتمية الاقليمي. } \\
& \text { وائل عبداله محمد، و ريم احمد عبدالعظيم. (2010). تصعيم الدنهج الددسي. عمان: دار الميسرة للنشر والتوزيع. } \\
& \text { وائل محمد ادريس، و طاهر محسن الغالبي. (2011). الادارة الاستراتيجية الدفاهيم .. العمليات (الإصدار 1). عمان: } \\
& \text { دار وائل للنشر والتوزيع. }
\end{aligned}
$$

Farzanege, H. M., \& Moosavi , S. (2010). Mazandaran Base Sports (swimming, track and field and gymnastics) Comparing and Examining (SWOT) and Presenting Guidelines. Physical Education and sport sciences first congress. Shariz: Islamic Azad University.

Hemmatinezhad M, \& Kahnazadeh S. (2009). Canoeing, Rowing \& Sailing Federation Strategic Programming.Tehran. Olympic National Academy. Management national gongress.

Thomas, J. R., \& Nelson, J. K. (1996). Research methods in physical education. USA: Human Kinetics. 
الملحق (1) الاستبانة قبد البحث بصورتها النهائية

\begin{tabular}{|c|c|c|c|c|c|c|}
\hline \multicolumn{5}{|c|}{ البدائل } & \multirow[b]{2}{*}{ 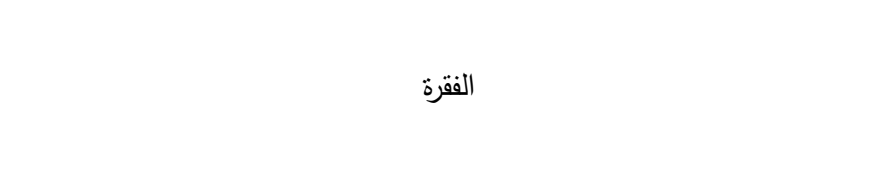 } & \multirow[b]{2}{*}{$ت$} \\
\hline لا اوافق & 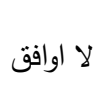 & 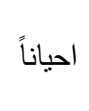 & اوافق & بشدة & & \\
\hline & & & & & توافر العدد الكافي من مدرسي التربية الرياضية بما يتتاسب مع اعداد الطلبة. & 1 \\
\hline & & & & & مدة الدرس الفعلية. & 2 \\
\hline & & & & & يضمن الدليل اثراك الطلبة كافة في الدرس. & 3 \\
\hline & & & & & تخصيص تجهيزات رياضية شخصية للمدرس سنويا. & 4 \\
\hline & & & & & تقبل ادارة المدرسة والمدرس. مضصات مالية تغطي ممارسة الألعاب والبرامج الرياضية كافة ذانيا من & 5 \\
\hline & & & & & يعطي مدرس التربية الرياضية محاضرات نظرية تعزز المواضيع العملية. & 6 \\
\hline & & & & & امكانية مدرس التربية الرياضية من تطبيق الدليل بكل محتوياته. & 7 \\
\hline & & & & & توكد إدارة المدرسة على العمل بالدليل. & 8 \\
\hline & & & & & يعد الدليل الخاص بالمرحلة المتوسطة مكملا لمنهاج المرحلة الابتدائية. & 9 \\
\hline & & & & & مفردات الدليل تتتاسب مع النشاطات اللاصفية في المدرسة (البطولات & 10 \\
\hline & & & & & تطبيق الدليل يساعد في تحديد ميول واتجاهات الطلبة نحو ممارسة الأنشطة & 11 \\
\hline & & & & & يتوافر في الدليل طرائق التدريس الحديثة. & 12 \\
\hline & & & & & تتعاون الإدارة الددرسية لتفعيل درس التربية الرياضية بالثكل الأمثل. & 13 \\
\hline & & & & & يتمكن الدليل من تامين تطوير القدرات البدنية والمهارية المختلفة. & 14 \\
\hline & & & & & يوفر الدليل امكانية تحيد نقاط القوة لدى الطلبة. & 15 \\
\hline & & & & & يغطي الدليل محتويات درس التربية الرياضية كافة. & 16 \\
\hline & & & & & يتفهم بشكل واضح مدرس التربية الرياضية تطبيق مفردات الدليل. & 17 \\
\hline & & & & & يوفر الدليل نماذج كافية من التدريبات لتتمية عناصر اللياقة البدنية لدى الطلبة. & 18 \\
\hline & & & & & يراعي الدليل الفروق الفردية بين البنين والبنات في الألعاب الرياضية & 19 \\
\hline & & & & & يوفر الدليل التغذية الراجعة لندعيم عملية التعلم والتعليم. & 20 \\
\hline & & & & & يوفر الدليل الاختبارات اللازمة لقياس مدى تعلم الطلبة للمهارات الرياضية. & 21 \\
\hline & & & & & يلائم الدليل لمستوى وقابليات الطلبة ومراحلهم العمرية. & 22 \\
\hline & & & & & توافر في الدليل تعليمات وارشادات صحية وكيفيه استخدام الإسعافات الأولية. & 23 \\
\hline & & & & & يوفر الدليل فرص ولقاءات ودية مع فرق الددارس الأخرى. & 24 \\
\hline & & & & & يوفر الدليل استخدام وسائل الايضاح الحديثة في نعليم المهارات للألعاب & 25 \\
\hline & & & & & يستفاد من وسائل الدعم المادي الخارجي لتعزيز درس التربية الرياضية. & 26 \\
\hline & & & & & يوفر الدليل نثاطات ترويحية للطلبة. & 27 \\
\hline & & & & & والصحية لأهداف التعليم. & 28 \\
\hline & & & & & توافر وسائل تقويمية لمعرفة مدى نجاح تطبيق الدليل لكل محتوياته. & 29 \\
\hline
\end{tabular}


مجلة التربية الرياضية - المجلد (32) - العدد (1) - سنة 2020.

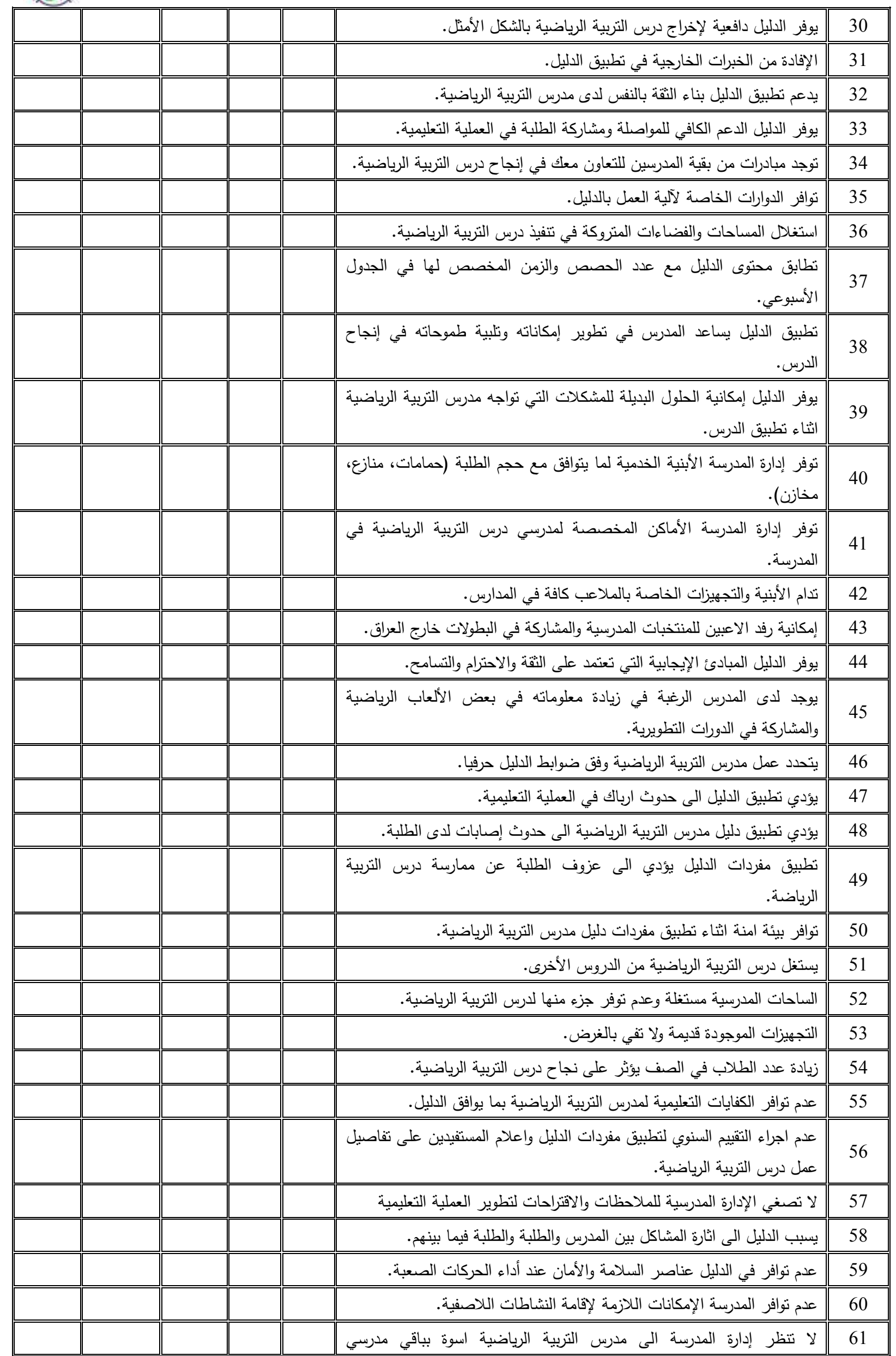


مجلة التربية الرياضية - المجلد (32) - العدد (1) - سنة 2020.

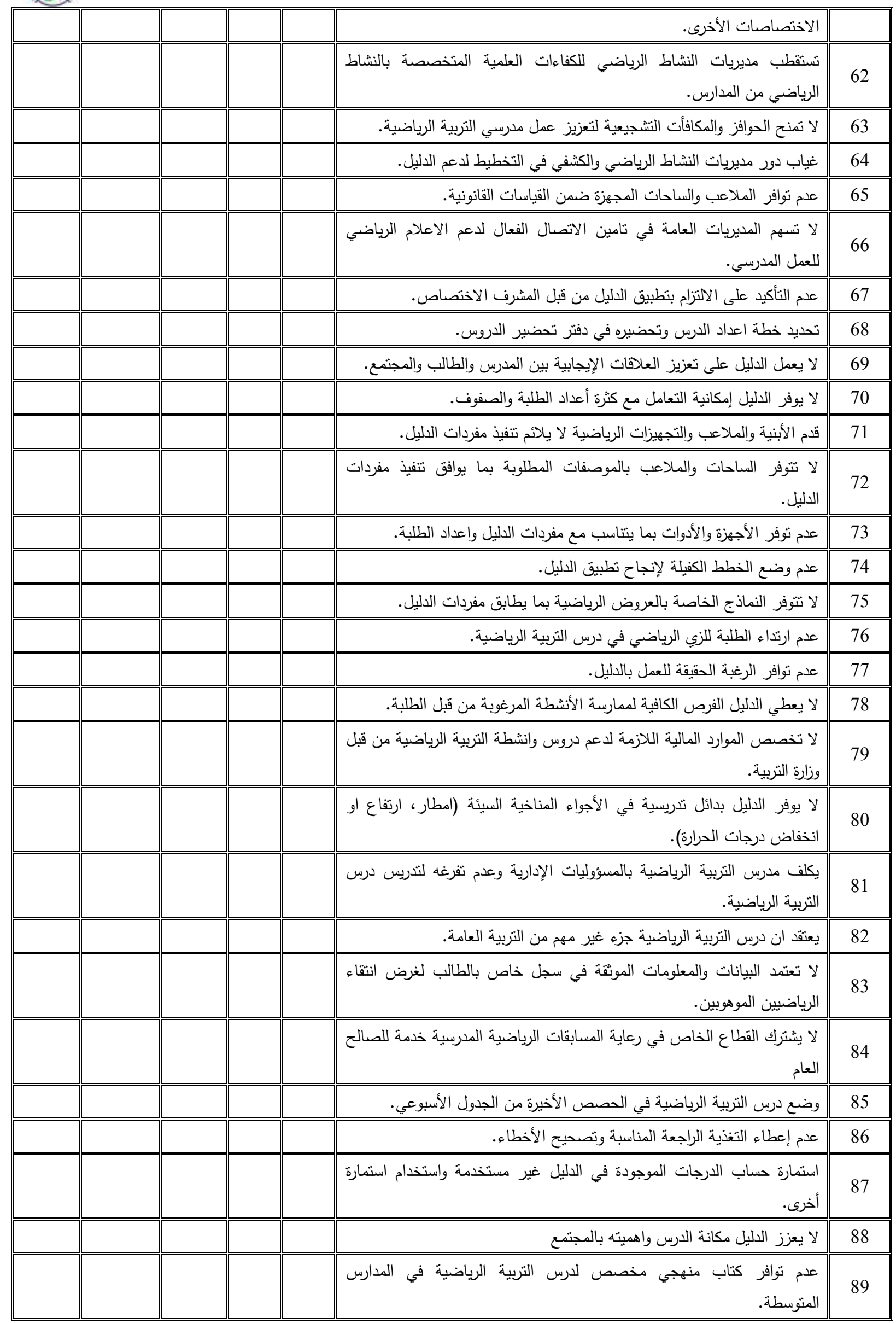

